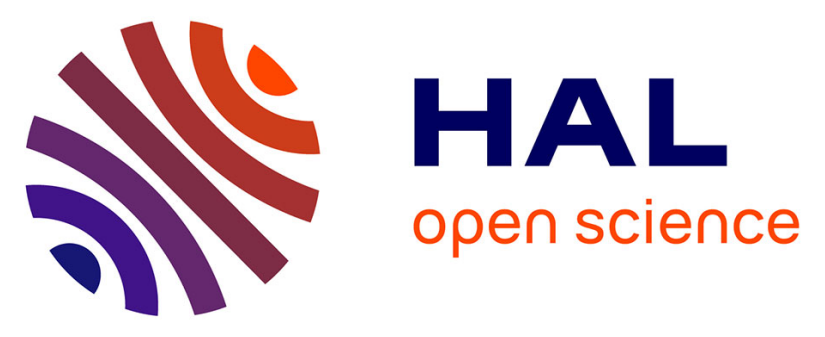

\title{
Time interval between infective endocarditis first symptoms and diagnosis: relationship to infective endocarditis characteristics, microorganisms and prognosis
}

Yohan N'guyen, Xavier Duval, Matthieu Revest, Matthieu Saada, Marie-Line Erpelding, Christine Selton-Suty, Coralie Bouchiat, François Delahaye, Catherine Chirouze, François Alla, et al.

\section{- To cite this version:}

Yohan N'guyen, Xavier Duval, Matthieu Revest, Matthieu Saada, Marie-Line Erpelding, et al.. Time interval between infective endocarditis first symptoms and diagnosis: relationship to infective endocarditis characteristics, microorganisms and prognosis. Annals of Medicine, 2016, 49, pp.117 - 125. 10.1080/07853890.2016.1235282 . hal-03267033

\section{HAL Id: hal-03267033 https://hal.science/hal-03267033}

Submitted on 28 Jun 2021

HAL is a multi-disciplinary open access archive for the deposit and dissemination of scientific research documents, whether they are published or not. The documents may come from teaching and research institutions in France or abroad, or from public or private research centers.
L'archive ouverte pluridisciplinaire HAL, est destinée au dépôt et à la diffusion de documents scientifiques de niveau recherche, publiés ou non, émanant des établissements d'enseignement et de recherche français ou étrangers, des laboratoires publics ou privés. 
Annals of Medicine

Original article

4

SANN-2016-0126 R1

5

Time Interval between Infective Endocarditis First Symptoms and

7 Diagnosis: Relationship to Infective Endocarditis characteristics, 
a Service de Médecine Interne, Maladies infectieuses et Immunologie Clinique, Hôpital Robert Debré, CHU Reims, Avenue du Général Koenig, 51100 Reims, France.

b Inserm CIC-1425 ; AP-HP, Hôpital Universitaire Bichat; Inserm UMR-1137 IAME; Université Paris Diderot, Paris 7, UFR de Médecine-Bichat, 16 Rue Henri Huchard, 75018 Paris, France.

${ }^{c}$ Maladies Infectieuses et Réanimation Médicale, Centre Hospitalier Universitaire, 2 Rue Henri le Guilloux, CIC-Inserm 1414 Université Rennes 1, 35000 Rennes, France.

${ }^{\mathrm{d}}$ Service de Maladies Infectieuses et Tropicales, Centre Hospitalier de Perpignan 20, Avenue du Languedoc - BP 4052, 66046 Perpignan, France.

e Inserm, CIC-1433 Epidemiologie Clinique \& CHU Nancy, Pôle S2R, Epidémiologie et Evaluation Cliniques, Nancy, F-54000, France.

${ }^{\mathrm{f}}$ Service de Cardiologie, Centre Hospitalier Régional Universitaire, Rue du Morvan, 54511 Vandoeuvre-lesNancy, France.

${ }^{\mathrm{g}}$ Centre National de Référence des Staphylocoques, 59 boulevard Pinel 69677 Bron, France.

h Université Claude Bernard, Lyon Hôpital Cardiologique Louis Pradel, 59 boulevard Pinel - 69677 Bron, 31 France.

i UMR 6249 Laboratoire Chrono-environnement Université de Bourgogne Franche-Comté, service de maladies infectieuses CHRU Besançon 3, bd Alexandre Fleming 25030 Besançon, France.

$34{ }^{j}$ Université de Lorraine, Université Paris Descartes, Apemac, EA4360 ; Inserm, CIC-1433, 9 avenue de la Forêt de Haye BP 184,54505 Vandoeuvre les Nancy, France.

$36{ }^{k}$ Cabinet d'infectiologie, Clinique Saint André-Groupe Courlancy, 5, boulevard de la Paix, 51100 Reims, 37 France.

$38{ }^{1}$ Université des Antilles et de la Guyane, Faculté de Médecine Hyacinthe Bastaraud, EA 4537; Inserm CIC1424, 39 Service de Maladies Infectieuses et Tropicales, Dermatologie, Médecine Interne, Centre Hospitalier 40 Universitaire de Pointe-à-Pitre/Abymes - BP 465, 97159 Pointe-à-Pitre, France.

$41{ }^{m}$ AEPEI Study group : see Annex 1. * These authors contributed equally to the work.

$42{ }^{£}$ corresponding author: Service de Médecine Interne, Maladies Infectieuses et Immunologie Clinique, Hôpital 43 Robert Debré CHU Reims, Avenue Général Koenig, 51100 Reims. Tel +33 326789422 . Fax +33 3267840 44 90. Mail: yohan.nguyen@wanadoo.fr. 
45 Abstract: (194 words)

46 Objective

47 To analyze the characteristics and outcome of infective endocarditis (IE) according to the time interval between IE first symptoms and diagnosis.

Methods

Among the IE cases of a French population-based epidemiological survey, patients having early-diagnosed IE (diagnosis of IE within 1 month of first symptoms) were compared to those having late-diagnosed IE (diagnosis of IE more than 1 month after first symptoms).

Results

Among the 486 definite-IE, 124 (25\%) had late-diagnosed IE whereas others had earlydiagnosed IE. Early-diagnosed IE were independently associated with female gender (OR = 1.8; $95 \%$ CI [1.0-3.0]), prosthetic valve $(\mathrm{OR}=2.6 ; 95 \% \mathrm{CI}[1.4-5.0])$ and staphylococci as causative pathogen $(\mathrm{OR}=3.7 ; 95 \% \mathrm{CI}[2.2-6.2])$. Cardiac surgery theoretical indication rates were not different between early and late-diagnosed IE (56.3\% vs $58.9 \%)$, whereas valve surgery performance was lower in early-diagnosed IE (41\% vs 53\%; p=0.03). In-hospital mortality rates were higher in early-diagnosed IE than in late-diagnosed IE (25.1\% vs $16.1 \%$;

$61 \mathrm{p}<0.001)$.

\section{Conclusions}

63 The time interval between IE first symptoms and diagnosis is closely related to the IE clinical presentation, patient characteristics and causative microorganism. Better prognosis reported in late-diagnosed IE may be related to a higher rate of valvular surgery.

66

67 Keywords: Infective endocarditis; acute; chronic; stroke; mortality; septic shock; cardiac surgery; prognosis. 
Key messages :

71

- Infective endocarditis, which time interval between first symptoms and diagnosis was less than one month, were mainly due to Staphylococcus aureus in France.

74

- Staphylococcus aureus infective endocarditis were associated with septic shock, transient ischemic attack or stroke and higher mortality rates than infective endocarditis due to other bacteria or infective endocarditis, which time interval between first symptoms and diagnosis was more than one month.

79

- Infective endocarditis, which time interval between first symptoms and diagnosis was more than one month, were accounting for one quarter of all infective endocarditis in our study and were associated with vertebral osteomyelitis and an higher rate of cardiac surgery performed for hemodynamic indication than other infective endocarditis. 
86

87

88

89

90

91

\section{Introduction}

Infective endocarditis (IE) is a rare but severe disease with an in-hospital mortality rate of around $20 \%$ (1) and a 5-year mortality rate of $40 \%$ (2). It also has a high morbidity and cost burden: its treatment requires prolonged hospitalization; one out of two patients undergoes valve surgery during the acute phase of the disease; and quality of life and return to work are compromised in some patients (3-4). These could be partly due to the delay induced by the difficulties in diagnosing this polymorphic disease.

For decades, IE had been classified according to its mode of presentation, which led to consider acute, subacute and chronic IE (5); without treatment, IE is a uniformly fatal disease and the old categories of acute, subacute and chronic disease only referred to the time it was anticipated to take before the patient would die. Following the dramatic changes in predisposing factors (decreased prevalence of rheumatic heart disease and increased prevalence of patients with prosthetic valve), in the source of microorganism acquisition (e.g. increased healthcare-associated acquisition) (6), and the improvement of outcome, classification of IE is now multifaceted, taking into account predisposing factors (native valve, prosthetic valve, intracavitary devices), the source of acquisition (community-acquired, healthcare-related), as well as the patient's background (intravenous drug user, elderly), with some overlap between the different classifications (1). These changes in IE categorization result in part from widespread access to new imaging techniques (7), including transthoracic and transesophageal echocardiography, which make it easier to diagnose IE earlier.

However, taking into account the time interval between the first symptom and the date of diagnosis of IE may hold an interest in terms of diagnostic and prognostic assessment of individual patients. In the case of non-acute IE, in which the prolonged time interval before diagnosis reflects the difficulties in diagnosing IE, the diagnostic delay may be associated with higher rates of cardiac lesions (destructive valve lesions, peri-annular abscess) or extra- 
111 cardiac complications (embolism, aneurysm) and consequently a worse outcome.

112 Furthermore, revisiting the description of initial symptoms may help practitioners diagnose IE

113 earlier in the era of these newer imaging techniques.

114 In this study, based on a large population-based survey on IE, we compared initial pre-

115 hospital symptoms, microbiological profile, patients' clinical status at the time of diagnosis,

116 the presence of an indication for surgical treatment and the overall IE prognosis in patients

117 whose IE was diagnosed less than 1 month after first symptoms (early-diagnosed IE) and in

118 patients whose IE was diagnosed more than one month after first symptoms (late-diagnosed

119 IE). 


\section{$121 \quad$ Patients and Methods}

122

123

124

125

126

127

128

129

130

131

132

133

134

135

136

137

138

139

140

141

142

143

144

145

\section{Design and patients}

For this study, we analyzed the database that had been created for the purpose of the French population-based epidemiological survey on definite IE in 2008, which methods and results have been published elsewhere (8). In brief, this survey had been conducted in seven regions of France (Paris, Lorraine, Rhône-Alpes, Franche-Comte, Marne, Ille-et-Vilaine, LanguedocRoussillon), a population pool of 16 million inhabitants, during a 12-month-period. During this period, all IE cases that were diagnosed in adult patients, before or after their referral to hospital, were reported. A standardized case report form (CRF) was prospectively filled out during the study and each reported case was then validated by an adjudication committee. All IE that were not classified as definite according to modified-Duke criteria (9) were excluded from further analysis.

\section{Collected data}

The data related to patients' background, IE initial symptoms, IE in-hospital data (clinical, biological, microbiological and echocardiography) and outcome (in-hospital and 1 year mortality) were extracted from the survey database.

Classification of IE based on its acquisition source (community-acquired, nosocomial and healthcare-related but non-nosocomial) had been performed as previously reported (10). Pre-hospital symptoms or symptoms at the time of IE diagnosis, which were recorded as open responses in the original CRF, were secondarily summarized into categorical variables. The presence of a severe sepsis or septic shock, of transient ischemic attack or of stroke was also recorded in the original epidemiological survey. The binary "severe sepsis/septic shock" variable was set at 'yes' whenever severe sepsis or septic shock - based on usual definitions (11) - was observed during the course of the disease. All foci of infection other than 
146 bloodstream, heart and presumed portal of entry were categorized as a "secondary site" of 147 infection.

Time interval between initial symptoms and diagnosis

150 Patients were assigned to the early-diagnosed IE group when diagnosis of IE was established

151 within 1 month of the first symptoms; patients were assigned to the late-diagnosed IE group 152 when diagnosis was established later than 1 month after the first symptoms. In patients with 153 community-acquired and non-nosocomial healthcare-related IE, such categorization was 154 calculated using time interval between first symptoms and the date of hospitalization (a proxy 155 for the date of diagnosis of IE); in patients with nosocomial healthcare-related IE, such 156 categorization was calculated using time interval between the date of the first symptoms and 157 the date of echocardiography. These time intervals were expressed in the original CRF as 158 qualitative variables: less or equal to one month, between 1 and 3 months or more than 3

159 months. In 9 cases of nosocomial healthcare-related IE, the time interval was categorized as 160 shorter than one month when the date of the first IE symptoms was doubtful. Moreover, to

161 better appreciate the time interval between symptoms and diagnosis of all early-diagnosed IE 162 (community-acquired, non-nosocomial health related and nosocomial IE), the time interval 163 was also calculated as difference between the calendar date of first symptoms and that of 164 hospitalization during which IE diagnosis was established, when these calendar dates of first symptoms and hospitalization were available and undoubtful in the original CRF.

167 Valve surgery

168 Theoretical indication for valve surgery during hospitalization had been determined by the treating physicians in each center and recorded prospectively in the original survey. For each 
170 patient, in each investigating center, an investigator had classified each patient as having a

171 theoretical indication for valve surgery according to current guidelines at the time of

172 diagnosis (12). These indications were defined as either hemodynamic (aortic or mitral valve

173 obstruction or aortic or mitral IE with fistula associated with heart failure or cardiogenic

174 shock and aortic or mitral severe regurgitation associated or not with heart failure or 175 cardiogenic shock), infectious (perivalvular abscess, persisting fever or positive blood 176 cultures), embolic (very large vegetations or large vegetations associated with previous 177 embolic event), or a combination of these, always in accordance with current guidelines at the 178 time of diagnosis (12). The performance of cardiac surgery was also prospectively recorded.

179

180

181

182

Mortality and outcome

The in-hospital mortality rate was defined as the number of patients with IE who died during the initial hospital stay, whatever the cause of death, divided by the study population. The allcause one-year mortality was also determined; the patient living status was obtained from patient's physician or, when not available, from the register of births and deaths.

\section{Statistical analysis}

Quantitative variables were expressed as mean \pm SD and qualitative variables were expressed as frequency and percent.

For intergroup comparison, we used ad hoc methods (1-way analysis of variance or Kruskal Wallis test for quantitative variables and Pearson chi-square test or Fisher exact test for qualitative variables), and 0.05 was the level of statistical significance.

All clinical characteristics of interest (among patients' background characteristics, presumed source of infection, IE valvular localization, microorganisms, vegetation size and 
195 intra-cardiac abscess existence) with a $\mathrm{p}$ value $<0.20$ were entered in a multivariate logistic

196 regression model to investigate factors independently associated with early-diagnosed IE. A

197 stepwise variable selection method was used with an enter $\mathrm{p}$ value of 0.2 and a remove $\mathrm{p}$

198 value of 0.05.All statistical analyses were performed using SAS (version 9.2) software (SAS

199 Institute Inc., Cary, NC, USA). 


\section{Results}

The data of 486 patients with definite IE were analyzed; of these, 356 patients had community-acquired, 105 had nosocomial, and 14 non-nosocomial healthcare-related IE; the presumed mode of acquisition was unknown in 11 patients.

\section{Time interval between initial symptoms and diagnosis}

Most patients (362 representing $74.5 \%$ of the entire cohort) had an early-diagnosed IE while $124(25.5 \%)$ had a late-diagnosed IE. Among the 235 early-diagnosed IE patients with available calendar date of the first symptom onset, the time interval between diagnosis of IE and first symptoms was less than 7 days in $70.2 \%$ of the patients, between 7 and 14 days in $17.5 \%$ and above 14 days in $12.3 \%$. Of note, in 42 of the 124 late-diagnosed IE patient group (33.9\%), first IE symptoms occurred more than 3 months before diagnosis.

\section{Clinical characteristics and causative microorganisms according to the time interval}

The clinical characteristics of IE according to the time to diagnosis are described in Table I. There was a lower proportion of males $(72.4 \%$ vs $83.1 \%, \mathrm{p}=0.01)$ and a higher proportion of intravenous drug users $(7.2 \%$ vs $2.4 \%, \mathrm{p}=0.05)$ in early-diagnosed IE than in late-diagnosed IE. Valve prosthesis IE (24\% vs $11.3 \%, \mathrm{p}=0.009)$ and nosocomial IE (24.8\% vs $12.1 \%$, $\mathrm{p}=0.007$ ) were more frequently observed in early-diagnosed IE than in late-diagnosed IE.

Causative microorganisms in early-diagnosed IE and late-diagnosed IE patients are reported in Table I and supplementary Table I. Among the 130 Staphylococcus aureus IE, 119 (91.5\%) occurred in early-diagnosed IE patients group. Among the 46 coagulase negative staphylococcus IE, 34 (73.9\%) occurred in early-diagnosed IE patients group (Figure 1) (supplementary Table I). Enterococci and group D streptococci were less frequently observed in early-diagnosed IE patients group, whereas pyogenic streptococci, $S$. pneumoniae, and $S$. 
agalactiae were almost exclusively observed in early-diagnosed IE. Other Streptococcus

species were equally distributed between early-diagnosed IE and late-diagnosed IE patients groups (supplementary Table I).

Factors independently associated with early-diagnosed IE were female sex $(\mathrm{OR}=1.8$;

95\% CI [1.0-3.0]), the presence of a prosthetic valve $(\mathrm{OR}=2.6 ; 95 \%$ CI $[1.4-5.0])$ and staphylococci as the causative pathogen $(\mathrm{OR}=3.7 ; 95 \%$ CI [2.2-6.2]).

234 Symptoms occurring before or at the time of IE diagnosis are reported in Table II. Fever, severe sepsis/ septic shock, and nausea were more frequently observed in early-diagnosed IE than in late-diagnosed IE. Mean C Reactive Protein was higher in early-diagnosed IE than in late-diagnosed IE. Weight loss and fatigue were less frequently observed in early-diagnosed IE than in late-diagnosed IE.

Valve surgery

241 Rates and types of theoretical indications for surgery were different according to groups. A 242 theoretical indication for valve surgery was less frequent in early-diagnosed IE patients. 243 Valve surgery was also less frequently performed (whether for heart failure or embolism 244 prevention) in early-diagnosed IE than in late-diagnosed IE (Table III).

\section{Mortality and outcome}

247 Table III presents IE complications and mortality rates in the early-diagnosed IE and late248 diagnosed IE patients groups and also according to the microorganism in the early-diagnosed

249 IE group. Early-diagnosed IE patients had more frequently septic shock, transient ischemic 250 attack or stroke; both in-hospital and one-year mortalities were higher in early-diagnosed IE 
251 than in late-diagnosed IE groups. Vertebral osteomyelitis was less frequently observed in 252 early-diagnosed IE than in late-diagnosed IE in-hospital.

253 In hospital mortality was higher in early-diagnosed IE patients than in late-diagnosed 254 IE patients (25.1 vs 16.1\%) such was one-year mortality (51.9\% vs 17.7\%) (Table III). 255 Among early-diagnosed IE group, Staphylococcus aureus species mainly accounted for in256 hospital or one-year mortalities, as well as for the presence of septic shock or transient 257 ischemic attack or stroke (Table III). Results were the same when the 11 late-diagnosed IE 258 due to Staphylococcus aureus (supplementary Table I) were removed from analysis (data not 259 shown). 
261

262

\section{Discussion}

In this large population-based study on definite IE focusing on the initial presentation of IE, we reported a marked difference in clinical presentation as well as in-hospital outcome which are related more to the nature of the microorganisms than intrinsically to the rapidity of diagnosis. Diagnosis of IE was established over one month after the beginning of symptoms in $25 \%$ of patients, and as long as 3 months in $8 \%$.

The design of this multiregional prospective population-based study allowed us to exclude referral bias and to properly assess the epidemiological and clinical presentation of IE. We could assume that clinical data presented here were robust enough to describe the diagnostic timeline and the polymorphic clinical presentation of IE. Despite the fact that the time interval between the first IE symptom and the diagnosis of IE depends in part on the healthcare system, which could vary according to country, we think that the clinical presentation of IE reported in the present study may be close to those of patients suffering from IE in other countries.

Early-diagnosed IE represents a heterogeneous population of IE patients, who can, based on our results, also be subdivided into two subgroups: early-diagnosed IE due to virulent bacterial species (such as Staphylococcus aureus and pyogenic streptoccocci) and early-diagnosed IE due to other bacteria. The first subgroup is composed of patients for whom the infectious and/or inflammatory manifestations of IE are prominent. These IE are mainly due to virulent microorganisms such as Staphylococcus aureus and pyogenic streptococci. Infectious manifestations (fever, septic shock...) lead to a sound presentation, and early diagnosis and care. As reported by others, this acute presentation is associated with a poor prognosis, with mortality rates over twice as high as in late-diagnosed IE (14). The overrepresentation of Staphylococcus aureus in this sub-group explains the high proportion of nosocomial infections, and of prosthetic valve IE. This high proportion of patients with 
prosthetic valve in the early-diagnosed IE (which is an independent associated factor for early-diagnosed IE) is also probably due to an earlier evocation of the possibility of IE in case of symptom occurrence in these patients clearly recognized at high incidence of IE. The high rate of early mortality and septic shock probably explains than almost one-third of patients theoretically having cardiac surgery indications finally did not undergo surgery. IE prognosis 291 in this subgroup of patients seems to be more related to control of the bacterial infection than 292 to valve dysfunction. These data support the interest of an empiric antibiotic strategy active 293 against Staphylococcus aureus and "virulent streptococci" in patients with acute IE, pending for blood culture results. The second sub-group of patients included in the early-diagnosed EI group has a clinical and microbiological profile which is quite similar to that of late296 diagnosed IE patients. It probably represents IE which has been diagnosed rapidly after the 297 onset of first symptoms despite a less symptomatic presentation, due to more specific initial 298 symptoms and/or greater practitioner attentiveness.

The late-diagnosed IE group accounted for one-quarter of all definite IE, and were

300 frequently associated with weight loss, and asthenia; late-diagnosed IE were mainly due to 301 non-virulent microorganisms such as oral or digestive streptococci on native valve diseases. 302 These data first suggested that intravenous ampicillin could be the drug of choice for 303 empirical treatment of late-diagnosed IE in the context of this study. Moreover, these data 304 also suggested that health education of patients with native valve disease could reduce the 305 time interval between symptoms like asthenia and diagnosis or between dental procedure and 306 diagnosis. Interestingly, fever was absent in more than $25 \%$ of cases (Table II); clinicians 307 should keep in mind the diagnosis of subacute IE and look for heart murmur abnormalities 308 when faced with asthenia or weight loss in patients with or without previous IE predisposing 309 cardiac conditions even without fever (15). In fact, the diagnosis of subacute IE still remains 310 difficult due to this non-specific and polymorphic clinical presentation. This is illustrated by 
311 the long time interval before diagnosis (more than 3 months after the beginning of symptoms)

312 in some patients. No clinical sign reported here was specific enough to help the clinician 313 easily make the diagnosis of IE. This long time interval before diagnosis of IE is associated 314 with a high rate of valve destruction, which had time to occur, and with a high rate of 315 indications for hemodynamic surgery, which was finally performed in most of the patients. 316 This assertion is confirmed by the data of DeSimone and colleagues, which provides evidence 317 of a higher diagnosis delay and a higher surgery rate in euthermic endocarditis than in febrile 318 endocarditis (15).

As demonstrated in our study, Staphylococcus aureus (which are responsible for earlydiagnosed IE) carried a poor prognosis as compared to all other patients, whether or not they 321 belonged to the early-diagnosed IE or to the late-diagnosed IE patients. Considering the 322 subgroup of oral streptococci IE, the chronicity of the infection is associated with high rates of valvular damage, valvular surgery which was both indicated and performed most often in this situation. The early-diagnosed versus late-diagnosed IE classification which was already debated fifty years ago (5), could remain of interest from a diagnostic point of view, because 326 it still underlines the persistent need for a high degree of suspicion of sub-acute endocarditis 327 in case of weight loss or asthenia in a community setting in patients without previously 328 known IE predisposing cardiac conditions. Moreover, the frequent occurrence of cardiac 329 surgery in late-diagnosed IE patients group without any significant increase of mortality 330 suggested that this time interval may also hold an interest in the evaluation of IE outcome in 331 further studies evaluating the impact of surgery on outcome of IE. We acknowledge several limitations to our study. First, the determination of initial symptoms has been obviously made a posteriori by patients and practitioners (but 334 prospectively in the study) and could be affected by recall bias. Furthermore, as most of these symptoms are non-specific, it is difficult to ascertain that they were really related to IE. 
336 Second, we did not take into account any microorganism virulence factors, which could differ

337 within microorganism species according to strain and could be responsible for the diversity of 338 IE presentations.

339 In the present report, the time interval to diagnosis of IE is closely related to the types

340 of IE clinical presentation, themselves closely related to patient characteristics,

341 microorganism virulence and capacity to induce severe inflammatory response syndrome, and

342 practitioner propensity for considering the possibility of IE diagnosis. Taken together, this

343 leads to distinct clinical IE presentations, with different treatment priorities, in which cardiac

344 surgery plays a major role. In non-Staphylococcus aureus IE, the late diagnosis resulting in

345 more extensive valve lesions (suggested by the higher rate of cardiac surgery performed for

346 hemodynamic indication) does not appear to impact prognosis, maybe because of frequent use

347 of valve surgery. Given the poor prognosis of IE, practitioners must be educated to evoke this

348 disease systematically, most obviously in case of septic presentation, but also in case of

349 atypical presentations whether or not fever is present. 


\section{Annex 1:}

AEPEI study group on Infective Endocarditis: Principal investigators: B. Hoen, X. Duval; Other members: F. Alla, A. Bouvet, S. Briançon, E. Cambau, M. Celard, C. Chirouze, N. Danchin, T. Doco-Lecompte, F. Delahaye, J. Etienne, B. Iung, V. Le Moing, JF. Obadia, C. Leport, C. Poyart, M. Revest, C. Selton-Suty, C. Strady, P. Tattevin, and F. Vandenesch.

Region study coordinating investigators: Y. Bernard, S. Chocron, C. Chirouze, B. Hoen, P. Plesiat, I. Abouliatim, C. De Place, P. Tattevin, M. Revest, P.Y Donnio, F. Alla, J.P Carteaux, T. Doco-Lecompte, C. Lion, N. Aissa, C. Selton-Suty, B. Baehrel, R. Jaussaud, P. Nazeyrollas, C. Strady, V. Vernet, E. Cambau, X. Duval, B. Iung, P. Nataf, C. Chidiac, M. Celard, F. Delahaye, J.F. Obadia, F. Vandenesch, H. Aumaître, J.M. Frapier, V. Le Moing, E. Oziol, A. Sotto, C. Sportouch.

Streptococci national reference center: C. Poyart, A. Bouvet

Staphylococci national reference center: F. Vandenesch. M. Celard, M. Bes

Investigators: P. Abassade, E. Abrial, C. Acar, N. Aissa JF. Alexandra, N. Amireche, D. Amrein, P. Andre, M. Appriou, MA. Arnould, P. Assayag, A. Atoui, F. Aziza, N. Baille, N. Bajolle, P. Battistella, S. Baumard, A. Ben Ali, J. Bertrand, S. Bialek, M. Bois Grosse, M. Boixados, F. Borlot, A. Bouchachi, O. Bouche, S. Bouchemal, JL. Bourdon, A. Bouvet, L. Brasme, F. Bricaire, E. Brochet, JF. Bruntz, A. Cady, J. Cailhol, MP. Caplan, B. Carette, JP. Carteaux, O. Cartry, C. Cazorla, M. Celard, H. Chamagne, H. Champagne, G. Chanques, J. Chastre, B. Chevalier, C. Chirouze, F. Chometon, C. Christophe, A. Cohen, N. Colin de Verdiere, N. Danchin, V. Daneluzzi, L. David, P. De Lentdecker, F. Delahaye, V. Delcey, P. Deleuze, E. Donal, X. Duval, B. Deroure, V. Descotes-Genon, , K. Didier Petit, A. Dinh, V. Doat, F. Duchene, F. Duhoux, M. Dupont, S. Ederhy, O. Epaulard, M. Evest, JF. Faucher, B. Fantin, E. Fauveau, T. Ferry, M. Fillod, T. Floch, T. Fraisse, JM. Frapier, L. Freysz, B. Fumery, B. Gachot, S. Gallien, I. Gandjbach, P. Garcon, A. Gaubert, JL. Genoud, S. Ghiglione, C. Godreuil, A. Grentzinger, L. Groben, D. Gherissi, P. Guéret, A. Hagege, N. Hammoudi, F. Heliot, P. Henry, S. Herson, B. Hoen, P. Houriez, L. Hustache-Mathieu, O. Huttin, S. Imbert, B. Iung, S. Jaureguiberry, M. Kaaki, A. Konate, JM. Kuhn, S. Kural Menasche, A. Lafitte, B. Lafon, F. Lanternier, V. Le Chenault, V. Le Moing, C. Lechiche, S. Lefevre, Thibaut, A. Lefort, A. Leguerrier, J. Lemoine, L. Lepage, C. Leport, C. Lepousé, J. Leroy, P. Lesprit, L. Letranchant, D. Loisance, G. Loncar, C. Lorentz, P. Mabo I. Magnin-Poull, T. May, A. Makinson, H. Man, M. Mansouri, O. Marçon, JP. Maroni, V. Masse, F. Maurier, M.C. Meyohas, PL. Michel, C. Michelet, F. Mechaï, O. Merceron, D. Messika-Zeitoun, Z. Metref, V. Meyssonnier, C. Mezher, S. Micheli, M. Monsigny, S. Mouly, B. Mourvillier, O. Nallet, P. Nataf, P. Nazeyrollas, V. Noel, J.F. Obadia, E. Oziol, T. Papo, B. Payet, A. Pelletier, P. Perez, JS. Petit, F. Philippart, E. Piet, C. Plainvert, B. Popovic, JM. Porte, P. Pradier, R. Ramadan, M. Revest, J. Richemond, M. Rodermann, M. Roncato, I. Roigt, O. Ruyer, M. Saada, J. Schwartz, C. Selton-Suty, M. Simon, B. Simorre, S. Skalli, F. Spatz, C. Strady, J. Sudrial, L. Tartiere, A. Terrier De La Chaise, MC. Thiercelin, D. Thomas, M. Thomas, L. Toko, F. Tournoux, A. Tristan, JL. Trouillet, L. Tual, A. Vahanian, F. Verdier, V. Vernet Garnier, V. Vidal, P. Weyne, M. Wolff, A. Wynckel, N. Zannad, PY. Zinzius.

Statistical analysis: F. Alla, ML Erpelding 


\section{Competing interests}

Funding:

This work was supported by a research grant from the French Ministry of Health, the support of the Société Française de Cardiologie, the European Society of Clinical Microbiology and Infectious Diseases and by Novartis. The sponsor was: Département à la Recherche Clinique et au Développement, Hôpital Universitaire de Besançon.

Role of the sponsor:

The sponsor (French ministry of health) supported the research but had no access to the data.

The authors report no conflicts of interest. 


\section{References}

1- Hoen B, Duval X. Clinical practice. Infective endocarditis. New Engl J Med 2013;368:1425-33

2- Bannay A, Hoen B, Duval X, Obadia JF, Selton-Suty C, Le Moing V et al. The impact of valve surgery on short- and long-term mortality in left-sided infective endocarditis: do differences in methodological approaches explain previous conflicting results? Eur Heart J 2011 Aug;32(16):2003-15.

3- Verhagen DW, Hermanides J, Korevaar JC, Bossuyt PM, van den Brink RB, Speelman P, et al. Health-related quality of life and posttraumatic stress disorder among survivors of left-sided native valve endocarditis. Clin Infect Dis 2009;48:1559-65.

4- Murray CJ, Vos T, Lozano R, Naghavi M, Flaxman AD, Michaud C et al. Disabilityadjusted life years (DALYs) for 291 diseases and injuries in 21 regions, 1990-2010: a systematic analysis for the Global Burden of Disease Study 2010. Lancet 2012; 380: 2197223

5- Hamburger M. Acute and Subacute Bacterial Endocarditis. Arch Intern Med 1963;112:12.

6- Fowler VG Jr, Miro JM, Hoen B, Cabell CH, Abrutyn E, Rubinstein E et al. Staphylococcus aureus endocarditis: a consequence of medical progress. JAMA 2005; 293:3012-21.

7- Bruun NE, Habib G, Thuny F, Sogaard P. Cardiac imaging in infectious endocarditis. Eur Heart J. 2014;35:624-32.

8- Selton-Suty C, Célard M, Le Moing V, Doco-Lecompte T, Chirouze C, Iung B et al. Preeminence of Staphylococcus aureus in infective endocarditis: a 1-year population-based survey. Clin Infect Dis 2012; 54 :1230-9. 
9- Li JS, Sexton DJ, Mick N, Nettles R, Fowler VG Jr, Ryan T et al. Proposed modifications to the Duke criteria for the diagnosis of infective endocarditis. Clin Infect Dis. 2000;30:633-8.

10- Friedman ND, Kaye KS, Stout JE, McGarry SA, Trivette SL, Briggs JP et al. Health careassociated bloodstream infections in adults: a reason to change the accepted definition of community-acquired infections. Ann Intern Med. 2002;137:791-7.

11- Jones AE, Puskarich MA. The Surviving Sepsis Campaign guidelines 2012: update for emergency physicians. Ann Emerg Med. 2014; 63(1):35-47.

12- Habib G, Hoen B, Tornos P, Thuny F, Prendergast B, Vilacosta I et al. Guidelines on the prevention, diagnosis, and treatment of infective endocarditis (new version 2009): the Task Force on the Prevention, Diagnosis, and Treatment of Infective Endocarditis of the European Society of Cardiology (ESC). Endorsed by the European Society of Clinical Microbiology and Infectious Diseases (ESCMID) and the International Society of Chemotherapy (ISC) for Infection and Cancer.Eur Heart J. 2009 ;30:2369-413.

13- Charlson ME, Pompei P, Ales KL, MacKenzie CR. A new method of classifying prognostic comorbidity in longitudinal studies: development and validation. J Chronic Dis. 1987;40(5):373-83.

14- Issa VS, Fabri J Jr, Pomerantzeff PM, Grinberg M, Pereira-Barreto AC, Mansur AJ. Duration of symptoms in patients with infective endocarditis. Int J Cardiol. 2003;89(1):6370.

15- DeSimone DC, Baddour LM, Lahr BD, Chung HH, Wilson WR, Steckelberg JM et al. Euthermic endocarditis. PLoS One. 2013;8:e80144. 


\section{Figure captions}

Figure 1: Repartition of microorganisms according to the time interval between first symptoms and diagnosis.

White bars: Late-diagnosed infective endocarditis (first IE symptoms occurring $>1$ months before diagnosis of infective endocarditis; $n=124$ )

Black bars: Early-diagnosed infective endocarditis (first IE symptoms occurring $\leq 1$ month before diagnosis of infective endocarditis; $n=362$ ) 
Table I: Clinical characteristics of the 486 patients according to time interval between first symptoms and diagnosis of definite infective endocarditis (IE).

\begin{tabular}{|c|c|c|c|c|}
\hline & $\begin{array}{l}\text { All IE } \\
n=486\end{array}$ & $\begin{array}{c}\text { Early-diagnosed } \\
\text { IE } n=362 \\
(74.5)\end{array}$ & $\begin{array}{c}\text { Late-diagnosed } \\
\text { IE } \mathrm{n}=124 \\
(25.5)\end{array}$ & $\mathbf{p}$ \\
\hline \multicolumn{5}{|l|}{ Background characteristics } \\
\hline Age (years) (mean \pm SD) & $62.4 \pm 15.9$ & $62.1 \pm 16.6$ & $63.3 \pm 13.7$ & 0.660 \\
\hline Male sex & $365(75.1)$ & $262(72.4)$ & $103(83.1)$ & 0.010 \\
\hline Charlson score $^{\circ}($ mean \pm SD $)$ & $1.9 \pm 2.2$ & $2.0 \pm 2.3$ & $1.7 \pm 2.1$ & 0.090 \\
\hline Malignancies & $87(17.9)$ & $63(17.4)$ & $24(19.4)$ & 0.070 \\
\hline Intravenous drug use & $29(6.0)$ & $26(7.2)$ & $3(2.4)$ & 0.050 \\
\hline \multicolumn{5}{|l|}{ IE characteristics } \\
\hline \multicolumn{5}{|l|}{ Presumed mode of acquisition of IE * } \\
\hline Community-acquired IE & $356(74.9)$ & $251(71.3)$ & $105(85.4)$ & \multirow[t]{3}{*}{0.007} \\
\hline Non nosocomial health related & $14(2.9)$ & $11(3.0)$ & $3(2.4)$ & \\
\hline Nosocomial IE & $105(22.1)$ & $90(24.8)^{\mathfrak{f}}$ & $15(12.1)$ & \\
\hline Previously known native valve disease & $130(26.1)$ & $91(25.1)$ & $39(31.5)$ & 0.009 \\
\hline Prosthetic valve IE & $101(20.8)$ & $87(24.0)$ & $14(11.3)$ & 0.009 \\
\hline Left-sided IE & $390(80.2)$ & 288 (79.6) & $102(82.3)$ & 0.510 \\
\hline Intracardiac device associated IE & $25(5.1)$ & $21(5.8)$ & $4(3.2)$ & 0.260 \\
\hline \multicolumn{5}{|l|}{ Microorganisms } \\
\hline Streptococci & $177(36.4)$ & 118 (32.6) & $59(47.6)$ & 0.0028 \\
\hline Oral streptococci & $91(18.7)$ & $58(16.0)$ & $33(26.6)$ & 0.0091 \\
\hline Group D streptococci & $62(12.8)$ & $37(10.2)$ & $25(20.2)$ & 0.0042 \\
\hline Pyogenic streptococci & $24(4.9)$ & $23(6.4)$ & $1(0.8)$ & 0.0139 \\
\hline Enterococci & $52(10.7)$ & $31(8.6)$ & $21(16.9)$ & 0.0092 \\
\hline Other Streptococcaceae & $8(1.6)$ & $5(1.4)$ & $3(2.4)$ & 0.4266 \\
\hline Staphylococcus aureus & $130(26.7)$ & $119(32.9)$ & $11(8.9)$ & $<0.0001$ \\
\hline Coagulase-negative staphylococci & $46(9.4)$ & $34(9.3)$ & $12(9.7)$ & 0.9254 \\
\hline Other microorganisms & $40(8.2)$ & $29(8.0)$ & $11(8.9)$ & 0.7636 \\
\hline$\geq 2$ Microorganisms & $9(1.9)$ & $6(1.7)$ & $3(2.4)$ & 0.6995 \\
\hline No microorganism identified & $24(4.9)$ & $20(5.5)$ & $4(3.2)$ & 0.3078 \\
\hline \multicolumn{5}{|l|}{ Vegetation size $\S$} \\
\hline$\leq 15 \mathrm{~mm}$ & $218(44.9)$ & $162(44.7)$ & $56(45.1)$ & \multirow{2}{*}{0.600} \\
\hline$>15 \mathrm{~mm}$ & $124(25.5)$ & $89(24.6)$ & $35(28.2)$ & \\
\hline Valvular or paravalular abscess & $100(20.6)$ & $79(21.8)$ & $21(16.9)$ & 0.430 \\
\hline
\end{tabular}

Note: Number (\%) or specified

Late-diagnosed infective endocarditis (first IE symptoms occurring $>1$ months before diagnosis)

Early-diagnosed infective endocarditis (first IE symptoms occurring $\leq 1$ month before diagnosis)

${ }^{\circ}$ Charlson score [13]

* In 11 patients, the mode of acquisition of IE was unknown.

${ }^{£}$ In 9 out of the 105 nosocomial IE, the time interval between first symptoms and IE diagnosis was doubtful and classified as shorter than 1 month.

$\S$ Missing data $=144(29.6)$ 
Table II: Clinical Symptoms and biological data (before hospitalization and at the time of diagnosis) of the 486 patients according to the time delay between first symptoms and diagnosis of definite Infective Endocarditis (IE).

\begin{tabular}{lcccc}
\hline Clinical symptoms & $\begin{array}{c}\text { All IE } \\
\mathbf{n = 4 8 6}\end{array}$ & $\begin{array}{c}\text { Early-diagnosed } \\
\text { IE } \mathbf{n = 3 6 2}\end{array}$ & $\begin{array}{c}\text { Late-diagnosed } \\
\text { IE } \mathbf{n = 1 2 4}\end{array}$ & $\mathbf{p}$ \\
\hline Patients' reported symptoms & & & & \\
$\quad$ Fever & $395(81.4)$ & $303(83.9)$ & $92(74.2)$ & 0.016 \\
$\quad$ Fatigue & $158(32.5)$ & $95(26.2)$ & $63(50.8)$ & $<0.0001$ \\
Weight loss & $134(27.6)$ & $75(20.7)$ & $59(47.6)$ & $<0.0001$ \\
\hline Pain & $15(3.1)$ & $13(3.6)$ & $2(1.6)$ & 0.374 \\
$\quad$ Headache & $19(3.9)$ & $18(5.0)$ & $1(0.8)$ & 0.055 \\
$\quad$ Thoracic pain & $18(3.7)$ & $11(3.0)$ & $7(5.6)$ & 0.180 \\
$\quad$ Abdominal pain & $49(9.9)$ & $32(8.8)$ & $16(12.9)$ & 0.190 \\
$\quad$ Rachialgia & $25(5.1)$ & $23(6.4)$ & $2(1.6)$ & 0.039 \\
Nausea/Vomiting & $21(4.3)$ & $15(4.1)$ & $6(4.8)$ & 0.742 \\
Cough & $103(21.2)$ & $78(21.5)$ & $25(20.2)$ & 0.744 \\
Dyspnea & & &
\end{tabular}

\section{IE manifestations}

\begin{tabular}{|lcccc|}
\hline Congestive heart failure & $173(35.6)$ & $132(36.5)$ & $41(33.1)$ & 0.495 \\
\hline Extra cerebral embolism & $21(4.3)$ & $16(4.4)$ & $5(4.0)$ & 0.854 \\
\hline Transient ischemic attack or stroke & $21(4.3)$ & $17(4.7)$ & $4(3.2)$ & 0.480 \\
\hline Severe sepsis/septic shock & $54(11.1)$ & $48(13.3)$ & $6(4.8)$ & 0.010 \\
\hline Secondary site of infection & $83(17.1)$ & $56(15.5)$ & $27(21.8)$ & 0.107 \\
\hline Splenomegaly & $41(8.4)$ & $28(7.7)$ & $13(10.5)$ & 0.341 \\
\hline
\end{tabular}

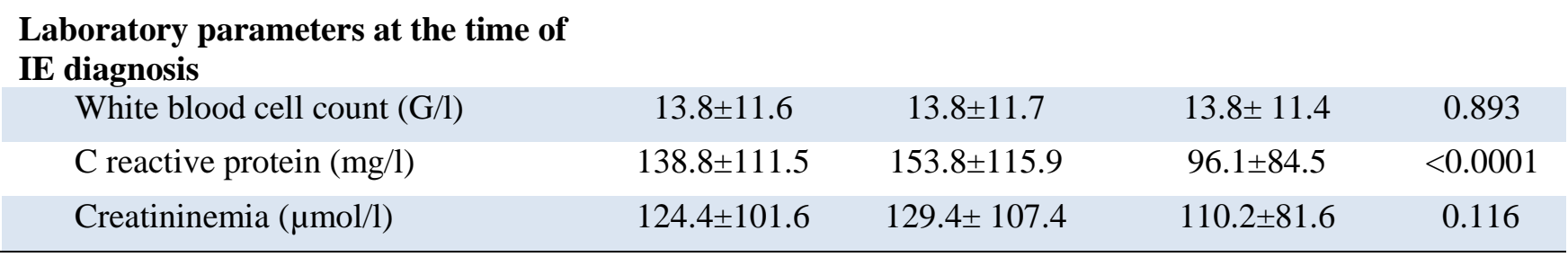

Note: Late-diagnosed infective endocarditis (first IE symptoms occurring $>1$ months before diagnosis)

Early-diagnosed infective endocarditis (first IE symptoms occurring $\leq 1$ month before diagnosis) 
Table III: Valve surgery, mortality and complications according to Staphylococcus aureus species and to time interval between first symptoms and diagnosis of definite Infective Endocarditis (IE).

\begin{tabular}{|c|c|c|c|c|c|c|}
\hline & $\begin{array}{c}\text { Early- } \\
\text { diagnosed IE } \\
n=362\end{array}$ & $\begin{array}{c}\text { Early-diagnosed IE } \\
\text { (S. aureus) } \\
\mathbf{n = 1 1 9}(\mathbf{3 2 . 9})\end{array}$ & $\begin{array}{c}\text { Early-diagnosed IE } \\
\text { (other microorganisms) } \\
n=243(67.1)\end{array}$ & $\begin{array}{c}\text { Late-diagnosed IE } \\
\mathbf{n}=\mathbf{1 2 4}\end{array}$ & $\mathbf{P} \S$ & $\mathbf{P}^{*}$ \\
\hline Age & $62.1 \pm 16.5$ & $59.8 \pm 18.4$ & $63.2 \pm 15.4$ & $63.3 \pm 13.7$ & 0.22 & 0.95 \\
\hline Charlson score $($ mean $\pm \mathrm{SD})$ & $2.03 \pm 2.29$ & $1.98 \pm 2.22$ & $2.05 \pm 2.32$ & $1.7 \pm 2.1$ & 0.21 & 0.10 \\
\hline Septic shock $* *$ & $72(19.9)$ & $40(33.6)$ & $32(13.2)$ & $8(6.5)$ & $<0.0001$ & 0.05 \\
\hline Transient ischemic attack or stroke** & $92(25.4)$ & $35(29.4)$ & $57(23.5)$ & $20(16.1)$ & 0.01 & 0.10 \\
\hline Vertebral osteomyelitis & $21(5.8)$ & $8(6.7)$ & $13(5.3)$ & $18(14.5)$ & 0.05 & 0.0078 \\
\hline Cardiac surgery theoretical indication & $204(56.3)$ & $63(52.9)$ & $141(58.0)$ & $73(58.9)$ & 0.35 & 0.87 \\
\hline $\begin{array}{l}\text { Type of cardiac surgery theoretical indication } \\
\text { - hemodynamic }\end{array}$ & $119(32.8)$ & $27(22.7)$ & $92(37.9)$ & $58(46.8)$ & $<0.0001$ & 0.10 \\
\hline - infectious & $91(25.1)$ & $32(26.9)$ & $59(24.3)$ & $26(21.0)$ & 0.28 & 0.47 \\
\hline - embolism prevention & $77(21.2)$ & $33(27.7)$ & $44(18.1)$ & $36(29.0)$ & 0.82 & 0.01 \\
\hline Valvular surgery performed & $151\left(41.7 / 74.0^{\circ}\right)$ & $44\left(37.0 / 69.8^{\circ}\right)$ & $107\left(44.0 / 75.8^{\circ}\right)$ & $66\left(53.2 / 90.4^{\circ}\right)$ & 0.01 & 0.09 \\
\hline In-hospital mortality & $91(25.1)$ & $48(40.3)$ & $43(17.7)$ & $20(16.1)$ & $<0.0001$ & 0.70 \\
\hline One year mortality & $118(51.9)$ & $56(47.1)$ & $62(25.5)$ & $22(17.7)$ & $<0.0001$ & 0.09 \\
\hline
\end{tabular}

\section{Note:}

Number and $(\%)$ or specified;

Late-diagnosed infective endocarditis (first IE symptoms occurring $>1$ months before diagnosis)

Early-diagnosed infective endocarditis (first IE symptoms occurring $\leq 1$ month before diagnosis)

S. aureus: Staphylococcus aureus

$\S$ p value when Early-diagnosed IE due to S. aureus were compared to Late-diagnosed IE

$*$ p value when Early-diagnosed IE due to all microorganisms except $S$. aureus were compared to Late-diagnosed IE

** including initial presentation and following events

${ }^{\circ}$ rate as compared to the number of patients with theoretical indications. 
Supplementary Table I: Streptococci and Staphylococci species involved in microbiologically documented Infective Endocarditis (IE) $(n=413)$ according to time interval between first symptoms and diagnosis of IE.

\begin{tabular}{|c|c|c|}
\hline Streptococcaceae & $\begin{array}{c}\text { Early-diagnosed IE } \\
n=154(65.0 \%)\end{array}$ & $\begin{array}{c}\text { Late-diagnosed IE } \\
\mathbf{n}=\mathbf{8 3}(\mathbf{3 5 . 0 \%})\end{array}$ \\
\hline Pyogenic streptococci & $31(20.1 \%)$ & $1(1.2 \%)$ \\
\hline Streptococcus pyogenes & $2(1.3 \%)$ & $0(0 \%)$ \\
\hline Streptococcus agalactiae & $13(8.4 \%)$ & $1(1.2 \%)$ \\
\hline Streptococcus dysgalactiae subsp. equisimilis & $8(5.2 \%)$ & $0(0 \%)$ \\
\hline Streptococcus pneumoniae & $8(5.2 \%)$ & $0(0 \%)$ \\
\hline Digestive streptococci & $63(40.9 \%)$ & $41(49.4 \%)$ \\
\hline Streptococcus gallolyticus & $25(16.2 \%)$ & $19(22.9 \%)$ \\
\hline Streptococcus infantarius & $2(1.3 \%)$ & $0(0 \%)$ \\
\hline Streptococcus lutetiensis & $1(0.6 \%)$ & $1(1.2 \%)$ \\
\hline Streptococcus pasteurianus & $4(2.6 \%)$ & $0(0 \%)$ \\
\hline Enterococcus faecalis & $29(18.8 \%)$ & $19(22.9 \%)$ \\
\hline Enterococcus faecium & $2(1.3 \%)$ & $2(2.4 \%)$ \\
\hline Other streptococci & $60(39.0 \%)$ & $41(49.4 \%)$ \\
\hline Abiotrophia defectiva & $1(0.6 \%)$ & $0(0 \%)$ \\
\hline Aerococcus viridans & $0(0 \%)$ & $1(1.2 \%)$ \\
\hline Gemella sanguinis & $1(0.6 \%)$ & $0(0 \%)$ \\
\hline Gemella sp. & $1(0.6 \%)$ & $1(1.2 \%)$ \\
\hline Granulicatella adiacens & $2(1.3 \%)$ & $1(1.2 \%)$ \\
\hline Streptococcus anginosus & $3(1.9 \%)$ & $4(4.8 \%)$ \\
\hline Streptococcus australis & $0(0 \%)$ & $1(1.2 \%)$ \\
\hline Streptococcus constellatus & $1(0.6 \%)$ & $0(0 \%)$ \\
\hline Streptococcus cristatus & $1(0.6 \%)$ & $0(0 \%)$ \\
\hline Streptococcus gordonii & $4(2.6 \%)$ & $5(6.0 \%)$ \\
\hline Streptococcus gr unspecified specie & $5(3.2 \%)$ & $5(6.0 \%)$ \\
\hline Streptococcus mitis & $8(8.2 \%)$ & $3(3.6 \%)$ \\
\hline Streptococcus mitis/oralis & $1(0.6 \%)$ & $1(1.2 \%)$ \\
\hline Streptococcus mutans & $3(1.9 \%)$ & $1(1.2 \%)$ \\
\hline Streptococcus oligofermentans & $1(0.6 \%)$ & $0(0 \%)$ \\
\hline Streptococcus oralis & $18(11.7 \%)$ & $8(9.6 \%)$ \\
\hline Streptococcus parasanguis & $1(0.6 \%)$ & $1(1.2 \%)$ \\
\hline Streptococcus salivarius & $4(2.6 \%)$ & $3(3.6 \%)$ \\
\hline Streptococcus sanguinis & $5(3.2 \%)$ & $4(4.8 \%)$ \\
\hline Streptococcus sp. & $0(0 \%)$ & $2(2.4 \%)$ \\
\hline Staphylococcaceae & $\begin{array}{c}\text { Early-diagnosed IE } \\
n=153(86.9 \%)\end{array}$ & $\begin{array}{c}\text { Late-diagnosed IE } \\
n=23(13.1 \%)\end{array}$ \\
\hline Staphylococcus aureus & $119(77.8 \%)$ & $11(47.8 \%)$ \\
\hline Coagulase negative staphylococci & $34(22.2 \%)$ & $12(52.2 \%)$ \\
\hline Staphylococcus capitis & $2(1.3 \%)$ & $1(4.3 \%)$ \\
\hline Staphylococcus epidermidis & $24(15.7 \%)$ & $9(39.1 \%)$ \\
\hline Staphylococcus haemolyticus & $1(0.7 \%)$ & $1(4.3 \%)$ \\
\hline Staphylococcus lugdunensis & $3(2.0 \%)$ & $1(4.3 \%)$ \\
\hline Staphylococcus sp. & $4(2.6 \%)$ & $0(0.0 \%)$ \\
\hline
\end{tabular}

Note: Late-diagnosed infective endocarditis (first IE symptoms occurring $>1$ months before diagnosis)

Early-diagnosed infective endocarditis (first IE symptoms occurring $\leq 1$ month before diagnosis) 